
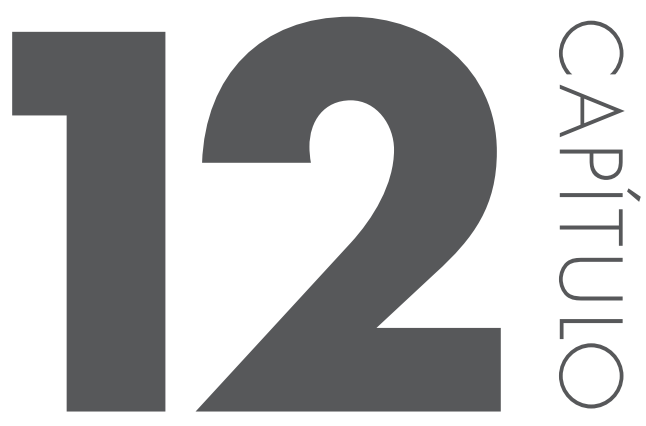

\title{
ANÁLISE DA DEMANDA E SINISTRALIDADE DO SEGURO PRESTAMISTA
}

Fabiana Lopes da Silva '; Betty Lilian Chan ${ }^{2}$

1 Professora do Departamento de Atuária e Métodos Quantitativos da PUC-SP e da Faculdade FIPECAFI.

2 Professora do Programa de Mestrado da FECAP e de Cursos de MBA da FIPECAFI.

\section{RESUMO}

O ramo de seguro prestamista tem se destacado no mercado brasileiro e chamado à atenção tanto da sociedade, em termos de proteção financeira, como das entidades seguradoras, quanto ao seu potencial de crescimento e lucratividade. Assim, o objetivo desta pesquisa é identificar possíveis variáveis relevantes para a sua demanda, bem como avaliar como a sinistralidade se comporta frente à taxa de desemprego. Os resultados dos testes sugerem que o efeito da taxa de desemprego tende a refletir na sinistralidade do seguro prestamista com defasagem de 2 meses. Além disso, os resultados indicaram que as variáveis 
de (a) concessões de crédito com recursos livres - pessoas físicas, (b) taxa de desemprego, (c) vendas de móveis e eletrodomésticos e (d) vendas de vestuário, embora com efeitos defasados, são relevantes para prever o comportamento da demanda do seguro prestamista.

Palavras-chaves: seguro prestamista, proteção financeira, risco. 


\section{INTRODUC̣ÃO}

O seguro é um instrumento criado pelo homem como forma de transferência ou minimização do risco decorrente de eventos aleatórios danosos, sendo o seu pressuposto básico o conceito de mutualismo.

O presente estudo trata de um tipo específico de seguro de pessoas, mais precisamente, o seguro prestamista. Normalmente, esse tipo de seguro cobre parte ou integralmente a amortização da dívida ou compromisso financeiro contraído pelo segurado em caso de ocorrência de desemprego involuntário, incapacidade, morte ou invalidez. Outras coberturas acessórias podem ser comercializadas juntas a esse produto.

Cabe destacar que um dos principais fatores que influenciam na sinistralidade desse segmento é o de desemprego, visto que sua frequência, normalmente, é superior aos demais riscos cobertos.

Além disso, em seguro, um aumento rápido dos prêmios deve ser analisado com cautela, pois pode indicar padrões de subscrição muito indulgentes e/ ou inadequados, que podem comprometer a solvência no longo prazo da Companhia, dado que os custos das operações, muitas vezes, podem demorar anos até que se tornem efetivamente conhecidos.

Como em qualquer atividade econômica, a solvência pressupõe o equilíbrio entre receitas e despesas. Nessa linha, para a manutenção das Sociedades Seguradoras, é necessário que haja um equilíbrio entre prêmios e sinistros, refletidos na sinistralidade.

Para uma gestão eficiente, é necessário monitorar as variáveis relevantes que possam influenciar na sinistralidade da companhia, de maneira a permitir a identificação oportuna de desvios e de suas respectivas origens, viabilizando reparos no modelo atuarial.

Nesse sentido, o objetivo desta pesquisa é analisar o segmento de seguro prestamista com o intuito de identificar possíveis variáveis relevantes para a sua demanda, bem como avaliar como a sinistralidade se comporta frente à taxa de desemprego, divulgada pelo IBGE.

A importância desse tipo de estudo reside no fato da necessidade crescente de informações relevantes que auxiliam a melhora do processo de tomada de decisões e monitoramento de riscos. 


\section{A EVOLUC̣ÃO DO MERCADO SEGURADOR NO BRASIL}

O mercado segurador brasileiro teve início em 1808 com a abertura dos portos ao comércio internacional. Segundo o Anuário Estatístico de 1997 da Superintendência Nacional de Seguros Privados (SUSEP), a primeira companhia de seguros a funcionar no Brasil foi a "Companhias de Seguros BOA-FÉ", em 24 de fevereiro de 1808, cuja principal atividade era operar o seguro marítimo.

Em 1966, por meio do Decreto-lei n 73, de 21 de novembro de 1966, foram reguladas todas as operações de seguros e resseguros e instituído o Sistema Nacional de Seguros Privados, constituído pelo Conselho Nacional de Seguros Privados (CNSP); Superintendência de Seguros Privados (SUSEP); Instituto de Resseguros do Brasil (IRB); sociedades autorizadas a operar em seguros privados; e corretores habilitados. (SUSEP, 1997).

Sobre a principal justificativa para a criação do mercado segurador nacional, Contador et al (2000, p. 1) afirma:

Tal estímulo deveu-se a necessidade de criar Investidores
Institucionais que substituíssem à União na tarefa de gerar
poupança interna - capaz de ajudar o país no custeio de seus
investimentos com infraestrutura. Tal fato é bastante comum nos
países em desenvolvimento.

O mercado segurador brasileiro tem apresentado forte crescimento nos últimos, impulsionado, principalmente, pela estabilização da economia e aumento no consumo (CHAN, 2010).

Segundo Souza $(2006$, p. 14) a estabilidade econômica fez com que a população brasileira deixasse de se preocupar com os reajustes diários de preços e passasse a pensar mais no futuro. A mudança de comportamento foi um impulso para a expansão do setor de seguros, previdência e capitalização.

Essa evolução, pode ser constata pela Tabela 1 que apresenta os valores arrecadados com prêmios diretos no mercado de seguros no Brasil, entre 2001 a 2013, bem como os respectivos percentuais de participação no PIB. 
Tabela 1 - Evolução dos Prêmios Diretos de Seguros e Participação no PIB (\%)

\begin{tabular}{ccc}
\hline ANO & $\begin{array}{c}\text { PRÊMIOS DIRETOS } \\
\text { (VALORES EM RS MIL) }\end{array}$ & PARTICIPAÇ̃̃ NO PIB (\%) \\
\hline 2001 & $24.211 .622,00$ & $1,86 \%$ \\
\hline 2002 & $23.910 .777,00$ & $1,62 \%$ \\
\hline 2003 & $30.717 .421,00$ & $1,81 \%$ \\
\hline 2004 & $37.546 .345,00$ & $1,93 \%$ \\
\hline 2005 & $42.561 .865,00$ & $1,98 \%$ \\
\hline 2006 & $49.587 .528,00$ & $2,09 \%$ \\
\hline 2007 & $58.443 .093,00$ & $2,20 \%$ \\
\hline 2008 & $67.816 .374,00$ & $2,24 \%$ \\
\hline 2009 & $76.611 .206,00$ & $2,36 \%$ \\
\hline 2010 & $90.088 .893,00$ & $2,39 \%$ \\
\hline 2011 & $105.031 .660,00$ & $2,54 \%$ \\
\hline 2012 & $129.340 .524,00$ & $2,94 \%$ \\
\hline 2013 & $145.348 .303,00$ & $3,00 \%$ \\
\hline & &
\end{tabular}

Fonte: Susep (2014)

Conforme Tabela 1, observa-se que o mercado segurador apresentou significativa expansão nos últimos anos, passando de aproximadamente R \$ 24 bilhões de prêmios diretos em 2001 para R \$ 145 bilhões, demonstrando um crescimento de cerca de 504\% no período em análise.

Magalhães et al apud Macedo, Silva e Santos (2003) "esclarecem que o mercado de seguros no Brasil possui um incrível potencial de crescimento. Caracterizam a indústria de seguros como um investimento destinado a um investidor que possui características de longo prazo.”

Nesse sentido, seguros são estruturas financeiras com o objetivo de indenizar os segurados e seus beneficiários no caso de ocorrência de determinados eventos imprevisíveis que tenham impacto negativo sobre seus interesses. Para minimizar os impactos formalizam um contrato junto a seguradoras, na qual serão fixados os limites de cobertura, o prazo de vigência, o prêmio a ser pago à seguradora pela assunção dos riscos cobertos.

De acordo com a Norma Internacional de Contabilidade - IFRS 4 (que trata de contratos de seguros) contrato de seguro é "um contrato no qual 
uma parte (seguradora) aceita um risco de seguro significativo de uma outra parte (segurado), acordando compensá-lo no caso de um evento futuro incerto especificado (evento segurado) o afete adversamente."

Segundo Carneiro (2012, p. 71) "Para os indivíduos é financeiramente mais vantajoso contratar um seguro do que constituir individualmente uma reserva monetária para ser usada no caso da ocorrência de um dano financeiro imprevisto".

Assim, "o que torna o seguro financeiramente vantajoso e justo segurado e seguradoras é a sua estrutura de financiamento baseada no mutualismo" (CARNEIRO, 2012, p. 72).

O mutualismo significa solidariedade financeira entre segurados de um mesmo grupo, muitas vezes chamado de mutualidade. Ou seja, é um mecanismo de cooperação onde muitos indivíduos contribuem para que alguns possam utilizar os recursos de um fundo mútuo.

Cumpre notar também a necessidade de acompanhamento, monitoramento e gestão dos riscos que estão expostas as seguradoras, tendo em vista a garantia da solvência da entidade no longo prazo.

Para Castiglione (1997, p. 14) risco pode ser definido como "um evento aleatório, cuja ocorrência implica prejuízos econômicos".

Especificamente sobre o risco atuarial, o Society of Actuaries Committee on Actuarial Principles no documento Principles of Actuarial Science, as variáveis associada ao risco atuarial são a ocorrência, o momento e a severidade. Tais variáveis "tratam da potencialidade de um evento acontecer, da incerteza quanto ao momento da sua ocorrência e da magnitude do seu impacto" (CHAN, SILVA e MARTINS, 2010, p. 63).

O paradigma da teoria econômica tem como princípio básico que os indivíduos respondem a incentivos. No caso do mercado de seguros existem as denominadas assimetrias de informação entre os agentes econômicos. Dois problemas resultam da existência de assimetrias de informação entre os participantes desse mercado: risco moral e seleção adversa.

A seleção adversa é a seleção pela seguradora de um grupo de segurados com perfil de risco acima da média da população.

De acordo com Carneiro (2012, p. 78):

A seleção adversa pode ser definida genericamente como a entrada, numa determinada classe de risco de seguro, de segurados com risco muito acima daquele previsto nas premissas atuariais. A seleção adversa tende a ocorrer com mais frequência quando a classificação dos segurados por perfil de risco, por algum motivo, 
não é devidamente feita pela seguradora ou quando os potenciais segurados tendem a contratar o seguro somente quando sabem que tem grande chance de precisar da cobertura.

O risco moral surge quando o indivíduo, após contratar o seguro, modifica seu comportamento e passa a realizar ações que, se não houvesse o seguro, não praticaria. Quando isso ocorre, o segurado passa a alterar a probabilidade de ocorrência do risco coberto pelo seguro (CARNEIRO, 2012).

Tanto o risco moral quanto a seleção adversa tende a prejudicar o mutualismo feito de forma justa, ou seja, a solidariedade entre os segurados de um mesmo perfil de risco. Assim, o risco moral e a seleção adversa podem onerar excessivamente o custo do seguro pago pelos segurados.

Quanto a precificação de seguros, Silva apud Luccas Filho (2011, p. 9) enumera o que deve ser levado em consideração para o dimensionamento e formação dos preços:

- Valor esperado do sinistro;

- Despesas de comercialização a ser pagas;

- Despesas administrativas esperadas;

- Lucro a ser atingido;

- Impostos;

- Despesas esperadas com a cessão do risco, através de cosseguro e/ou resseguro;

- Resultado financeiro esperado;

- Oscilação do risco.

Entretanto, Myhr e Markham (2006, p.17) observam que um aumento rápido nos prêmios pode ser indesejável, haja vista que poderia indicar padrões inapropriados de subscrição de riscos ou adoção de níveis de precificação insuficientes.

Assim, para garantir a solvência da entidade seguradora, o prêmio a ser cobrado dos segurados deve ser calcado em técnicas e modelos adequados de precificação.

Diferentemente de outros segmentos, como indústria e comércio, no setor de seguros no momento da venda não se sabe de antemão qual será o real custo do custo do sinistro, pois "o custo das operações de seguros, muitas vezes, podem demorar vários anos até que se tornem efetivamente conhecidos" (CHAN, 2010, p. 8). 
Assim, a adoção de um modelo de precificação adequado é fundamental para garantir que o prêmio cobrado será suficiente para a cobertura dos sinistros esperados, com uma determinada margem de segurança. Nessa linha, é importante monitorar o comportamento das variáveis que influenciam na sinistralidade da Companhia, bem como entender os fatores determinantes da demanda do seguro.

\section{SEGURO PRESTAMISTA}

A situação financeira de um indivíduo pode ser comprometida em função da perda involuntária do emprego ou incapacidade, temporária ou não, levando-o a dificuldades para honrar o pagamento dos seus compromissos.

Assim, uma modalidade de seguro tem se destacado no mercado brasileiro, o chamado seguro prestamista. Esta modalidade de seguro, como o próprio nome sugere, garante proteção financeira para as pessoas que têm prestações a serem pagas, sejam ela decorrentes de empréstimos, financiamentos ou alguma outra dívida.

O seguro prestamista faz parte do ramo de seguro de pessoas. Segundo Guia de Orientação e Defesa do Segurado elaborado pela Susep (2006, p. 33), "o seguro de pessoas têm por objetivo garantir o pagamento de uma indenização ao segurado e aos seus beneficiários, observadas as condições contratuais e as garantias contratadas". São exemplos de seguros de pessoas, o seguro de vida, seguro funeral, seguro de acidentes pessoais, seguro educacional, seguro viagem, seguro de diária de internação hospitalar, seguro perda de renda, seguro de diária de incapacidade temporária e o seguro prestamista.

Assim, a principal diferença entre o seguro de pessoas e o de não-pessoas - por exemplo, seguro de danos patrimoniais e prestação de serviços - "é que não tem como se determinar ao certo o valor econômico da vida de alguém. Assim, os valores da indenização em caso de morte ou invalidez estabelecidos pelos seguros de pessoas têm de ser escolhidos pelo próprio indivíduo, e não pelo "valor de mercado", como no caso de bens e serviços" (SOUZA, 2002, p.62).

A Tabela 2 a seguir mostra a evolução dos prêmios diretos do seguro prestamista e quanto representa em termos de percentual do PIB. 
Tabela 2 - Participação do Seguro Prestamista Frente ao PIB Brasileiro

\begin{tabular}{cccc}
\hline ANO & PRÊMIOS DIRETOS & PIB (PREC OS CORRENTES) & \% PIB \\
\hline 2003 & $227.535 .487,76$ & $1.720 .069 .281 .000,00$ & $0,0132 \%$ \\
\hline 2004 & $526.581 .840,93$ & $1.958 .705 .300 .290,00$ & $0,0269 \%$ \\
\hline 2005 & $1.002 .050 .109,70$ & $2.171 .735 .600 .840,00$ & $0,0461 \%$ \\
\hline 2006 & $1.423 .325 .873,43$ & $2.409 .802 .753 .950,00$ & $0,0591 \%$ \\
\hline 2007 & $2.068 .437 .015,07$ & $2.718 .031 .637 .470,00$ & $0,0761 \%$ \\
\hline 2008 & $2.310 .131 .674,32$ & $3.107 .530 .777 .000,00$ & $0,0743 \%$ \\
\hline 2009 & $2.726 .299 .444,12$ & $3.328 .173 .595 .670,00$ & $0,0819 \%$ \\
\hline 2010 & $3.407 .937 .411,51$ & $3.886 .835 .000 .000,00$ & $0,0877 \%$ \\
\hline 2011 & $4.521 .967 .633,10$ & $4.374 .765 .000 .000,00$ & $0,1034 \%$ \\
\hline 2012 & $5.851 .467 .060,77$ & $4.713 .095 .979 .500,00$ & $0,1242 \%$ \\
\hline 2013 & $7.096 .285 .515,35$ & $5.157 .568 .999 .999,99$ & $0,1376 \%$ \\
\hline 2014 & $7.975 .995 .427,46$ & $5.521 .256 .074 .049,36$ & $0,1445 \%$ \\
\hline
\end{tabular}

Fonte: Elaborado a partir dos dados da Base SES da SUSEP e do Bacen

Conforme pode se observar, essa modalidade de seguro, objeto da presente pesquisa, tem, gradativamente, expandido no mercado brasileiro.

Segundo Susep (2006, p. 33) o seguro prestamista "é aquele no qual os segurados convencionam pagar prestações ao estipulante para amortizar dívida contraída ou para atender a compromisso assumido. O primeiro beneficiário é o próprio estipulante, pelo valor do saldo da dívida ou do compromisso. A diferença que ultrapassar o saldo será paga ao segundo beneficiário, indicado pelo segurado”.

O seguro prestamista, geralmente, apresenta as coberturas de morte, invalidez e perda de renda em decorrência de desemprego ou incapacidade total ou temporária.

Em geral, para a elegibilidade ao benefício em caso de desemprego e se tratando de trabalhadores em regime CLT, faz-se necessário atender alguns requisitos, dentre os quais tempo mínimo de carteira assinada com o mesmo empregador, normalmente 12 meses consecutivos até a data de demissão. Esse seguro também é vendido a profissionais autônomos onde deverá ser comprovada sua renda por meio do CCM (Cadastro de Contribuinte Mobiliário).

Além disso, na tentativa de minimizar a auto-seleção, é usual que as coberturas de desemprego e incapacidade prevejam carências. 
O desemprego é um assunto que merece atenção no Brasil, e é objeto de preocupação não só da sociedade como do governo, uma vez que se trata de um problema social. Segundo Chahad (1987, p. 21):

A existência de indivíduos "sem ocupação", isto é, sem desempenhar alguma atividade definida como "trabalho", é uma característica da sociedade dos seres humanos, qualquer que seja sua etapa histórica. Mas é só no estágio capitalista, onde a produção de bens e serviços se destaca pela utilização do trabalho assalariado, que essa situação se caracteriza como "desemprego", ou seja, podemos observar um indivíduo apto, disponível para o trabalho, mas este não é encontrado. Nesta perspectiva, o conceito de desemprego envolve uma dimensão histórica e reflete as relações sociais que se estabelecem no sistema capitalista de produção.

Segundo Mankiw (2005, p. 303):

Embora certo grau de desemprego seja inevitável em uma economia complexa, com milhares de empresas e milhões de trabalhadores, o nível de desemprego varia substancialmente ao longo do tempo e de país para país. Quando um país mantém seus trabalhadores o mais plenamente empregados possível, atinge um nível de PIB maior do que se deixasse muitos de seus trabalhadores ociosos.

Um dos principais motivos de indenização do seguro prestamista decorre da perda de emprego, dado que a frequência costuma ser maior que casos de invalidez ou morte, os quais também são coberturas usuais contempladas nesta modalidade de seguro.

Portanto, é importante saber como a sinistralidade do seguro prestamista responde a variações na taxa de desemprego para permitir antecipar a movimentos que, eventualmente, possam impactar no equilíbrio atuarial do produto.

O Gráfico 1 apresenta a taxa de desemprego aberto nas regiões metropolitanas no período de jan/2003 a fev/2015. A taxa de desemprego aberto ou taxa de desocupação calculada pela PME - Pesquisa Mensal de Emprego considera a percentagem das pessoas desocupadas em relação às pessoas economicamente ativas. Foram classificadas como desocupadas as pessoas que procuraram trabalho de maneira efetiva nos 30 dias anteriores ao da entrevista e não exerceram nenhum trabalho nos últimos 7 dias. A população 
economicamente ativa na semana de referência é constituída pelas populações ocupada e desocupada na semana de referência.

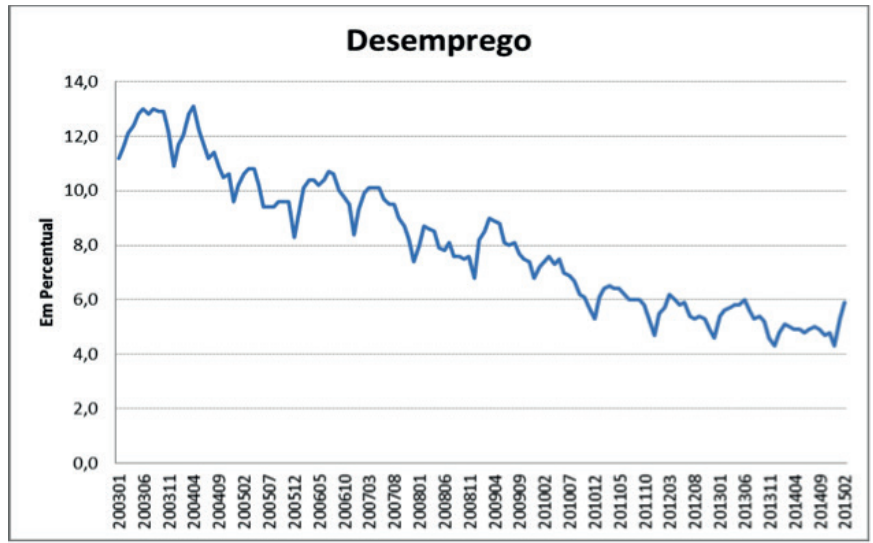

Gráfico 1 - Taxa de Desemprego Aberto nas regiões metropolitanas no período de 2003 a 2015

Fonte: IBGE

O Gráfico 2 mostra a evolução dos prêmios ganhos referente ao seguro prestamista.

A partir do Gráfico 2, pode-se observar a evolução significativa do prêmio ganho do seguro prestamista ao longo do período analisado.

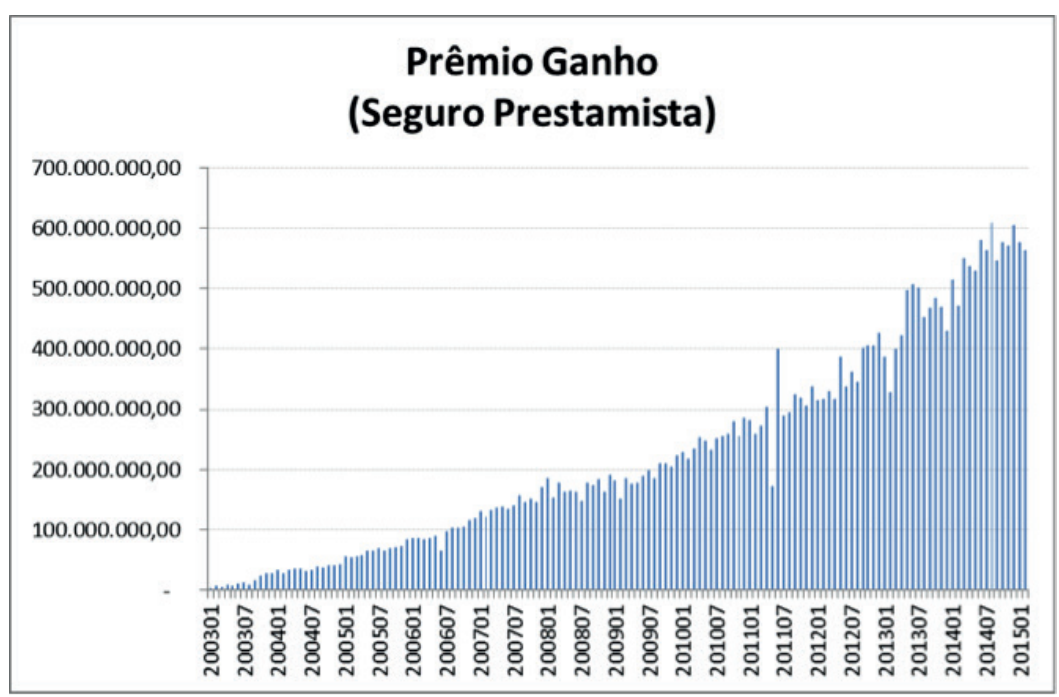

Gráfico 2 - Evolução do Prêmio Ganho no período de 2003 a 2015

Fonte: Elaborado a partir dos dados disponíveis na base SES divulgada pela SUSEP 


\section{METODOLOGIA E BASE DE DADOS}

A tipologia de pesquisa adotada se baseia, predominantemente, em uma abordagem empírico-analítica.

Para o desenvolvimento do presente estudo, obtiveram-se as seguintes séries históricas:

- Sinistralidade do seguro prestamista: série construída a partir da razão entre sinistro retido e prêmio ganho da base de dados SES divulgada pela SUSEP referente ao período de janeiro de 2003 a fevereiro de 2015. Cabe destacar que a partir de dezembro de 2013, o prêmio ganho passou a ser bruto de resseguro ao invés de líquido, como contabilizado anteriormente. Assim, também foi testada uma dummy de quebra estrutural na série nesta data;

- Variação do prêmio ganho do seguro prestamista: série construída a partir da base de dados SES divulgada pela SUSEP referente ao período de janeiro de 2003 a fevereiro de 2015. Conforme comentado, houve alteração no conceito de prêmio ganho a partir de dezembro de 2013 e, portanto, também foi testada uma dummy de quebra estrutural;

- Taxa de desemprego das regiões metropolitanas de Recife, Salvador, Belo Horizonte, Rio de Janeiro, São Paulo e Porto Alegre divulgada pelo IBGE;

- Volume de Vendas - Varejo. Índice Mensal que compara os índices de volume da Receita Bruta de Revenda do mês com os obtidos em igual mês do ano anterior referente a:

» Hipermercados, supermercados, produtos alimentícios, bebidas e fumo;

» Tecidos, vestuário e calcados;

" Móveis e eletrodomésticos.

- Concessões de crédito com recursos livres - Pessoas físicas;

- Inadimplência da carteira de crédito - Pessoas físicas - Total - \%;

- Expectativa do consumidor (INEC) - expectativa de renda pessoal - índice (média 2001 = 100) - Confederação Nacional da Indústria: Trata-se de uma série que era trimestral até o primeiro trimestre de 2010 e se tornou mensal a partir de abril de 2010. Ajuda a antecipar variações no ritmo da atividade econômica, uma vez que a avaliação do consumidor quanto à conjuntura antecede, e em boa parte determina variações no nível de consumo e poupança das famílias;

- Taxa de ocupação do IBGE: Mede a relação entre o número de pessoas ocupadas e o número de pessoas economicamente ativas na semana de referência. De acordo com o IBGE, a Pesquisa Mensal de Emprego - PME, implantada em 1980, produz indicadores para o acompanhamento conjuntural do mercado de trabalho nas regiões metropolitanas de Recife, Salvador, Belo Horizonte, Rio de 
Janeiro, São Paulo e Porto Alegre. Trata-se de uma pesquisa domiciliar urbana realizada por meio de uma amostra probabilística, planejada de forma a garantir os resultados para os níveis geográficos em que é realizada.

Gujarati (2006, p.529) explica que "Em economia, a dependência de uma variável Y (a variável dependente) em relação a uma ou mais variáveis $\mathrm{X}$ (variáveis explanatórias) raramente é instantânea. Muitas vezes, $\mathrm{Y}$ reage a X após um certo tempo. Esse intervalo é chamado de defasagem.

Nessa linha, o presente estudo fez uso de análise de regressão que envolve séries temporais, testando não apenas os valores correntes das variáveis explanatórias, como também os valores defasados (modelo de defasagens distribuídas), incluindo os valores defasados da variável dependente (modelo auto-regressivo).

Além disso, para estimação, foi utilizado o erro-padrão robusto desenvolvido por Newey-West. Trata-se de uma extensão dos erros-padrão consistentes para corrigir heterocedasticidade, incluindo autocorrelação.

Para analisar o objetivo de identificar possíveis variáveis relevantes para a demanda do seguro prestamista, testou-se a variação do prêmio ganho consolidado (variável dependente) contra as variáveis explicativas (no nível e até 12 defasagens): variação do PIB mensal (var_pib), concessões de crédito com recursos livres - Pessoas físicas (cred_livre_pf), Expectativa do consumidor de renda pessoal (expec_renda), taxa de ocupação (tx_ocupação), taxa de desemprego (desemp), crescimento de vendas de móveis e eletrodomésticos (eletro), crescimento de vendas de tecidos, vestuário e calçados (vestuario), crescimento de vendas de hipermercados, supermercados, produtos alimentícios, bebidas e fumo (hiper_super_alim) e inadimplência da carteira de crédito - Pessoas físicas (inadim_pf). Além disso, também foram testados valores defasados da própria variável dependente.

Cabe destacar que não foi utilizada como a variável resposta o próprio prêmio ganho, uma vez que tanto o teste Dickey Fuller Aumentado como o de Phillips Perron indicaram que se trata de uma série com raiz unitária, embora pelo teste KPSS o resultado seja diferente. Já, pelos mesmos 3 testes realizados, a série variação do prêmio ganho (var_premio) parece se tratar de uma série estacionária.

Para atender ao objetivo de avaliar como a sinistralidade se comporta frente à taxa de desemprego, divulgada pelo IBGE, além da regressão contra valores no nível e defasados desta variável, também foi testada valores defasados da própria variável dependente.

Para o desenvolvimento da presente pesquisa, foi utilizado o software Eviews. 


\section{ANÁLISE DOS RESULTADOS}

\subsection{POSSÍVEIS VARIÁVEIS RELEVANTES PARA A DEMANDA DE SEGURO PRESTAMISTA}

A série histórica utilizada para o desenvolvimento deste estudo é de janeiro de 2012 a fevereiro de 2015. A Tabela 3 mostra os resultados do modelo selecionado:

\section{Tabela 3 - Resultados do modelo de previsão da demanda}

\begin{tabular}{|c|c|c|c|c|}
\hline \multicolumn{5}{|c|}{$\begin{array}{l}\text { DEPENDENT VARIABLE: VAR_PREMIO } \\
\text { METHOD: LEAST SQUARES } \\
\text { DATE: } 05 / 02 / 15 \text { TIME: } 21: 24 \\
\text { SAMPLE: } 2012 M 012015 M 02 \\
\text { INCLUDED OBSERVATIONS: } 38 \\
\text { NEWEY-WEST HAC STANDARD ERRORS \& COVARIANCE (LAG TRUNCATION=3) }\end{array}$} \\
\hline VARIABLE & COEFFICIENT & STD. ERROR & T-STAIISTIC & PROB. \\
\hline $\begin{array}{l}\text { C } \\
\text { VAR_PREMIO(-1) } \\
\text { CRED_LIVRE_PF(-5) } \\
\text { DESEMP(-2) } \\
\text { ELETRO(-6) } \\
\text { VESTUARIO(-2) }\end{array}$ & $\begin{array}{l}-1.287067 \\
-0.523101 \\
0.006125 \\
0.089131 \\
0.007548 \\
0.009566\end{array}$ & $\begin{array}{l}0.486850 \\
0.091456 \\
0.002017 \\
0.046196 \\
0.002864 \\
0.002109\end{array}$ & $\begin{array}{l}-2.643663 \\
-5.719695 \\
3.036913 \\
1.929417 \\
2.635567 \\
4.536252 \\
\end{array}$ & $\begin{array}{l}0.0126 \\
0.0000 \\
0.0047 \\
0.0626 \\
0.0128 \\
0.0001\end{array}$ \\
\hline $\begin{array}{l}\text { R-SQUARED } \\
\text { ADJUSTED R-SQUARED } \\
\text { S.E. OF REGRESSION } \\
\text { SUM SQUARED RESID } \\
\text { LOG LIKELLHOOD } \\
\text { DURBIN-WATSON STA }\end{array}$ & $\begin{array}{l}0.530748 \\
0.457427 \\
0.070514 \\
0.159110 \\
50.11947 \\
1.988519\end{array}$ & \multicolumn{2}{|c|}{$\begin{array}{l}\text { MEAN DEPENDENT VAR } \\
\text { S.D. DEPENDENT VAR } \\
\text { AKAIKE INFO CRITERION } \\
\text { SCHWARZ CRITERION } \\
\text { F-STATISTIC } \\
\text { PROB(F-STATISTIC) }\end{array}$} & $\begin{array}{l}0.017761 \\
0.095729 \\
-2.322077 \\
-2.063511 \\
7.238716 \\
0.000124\end{array}$ \\
\hline
\end{tabular}

A variável dummy de quebra estrutural por conta da alteração do conceito de de prêmio ganho em dezembro de 2013 não foi significativa. O seguro prestamista é um seguro massificado e as seguradoras, em geral, trabalham com baixa taxa de resseguro para esse segmento, o que justifica o fato da variável dummy não ter sido significativa.

A defasagem da própria variável explicativa foi inserida no modelo para evitar que os resíduos disponham de alguma estrutura/viés, tornando-os ruídos brancos, conforme Figura 1.

Além do teste de Durbin-Watson para autocorrelação dos resíduos de primeira ordem, foi realizado o teste de Ljung Box (ver correlograma). Os resultados dos testes efetuados indicaram a ausência de autocorrelação serial ao nível de significância de 5\%. 
Para testar a normalidade dos resíduos, fez uso do teste Jarque Bera, conforme Gráfico 3.

Os resultados do teste de Jarque Bera indicam que não há indícios de que a distribuição dos resíduos não sejam normais ao nível de significância de $5 \%$.

Também foi testada a correlação entre o resíduo do modelo e as variáveis explicativas e nenhuma foi significativa. Pelo Fatores de Inflacionamento da Variância (VIF) não foi identificado problema de multicolinearidade.

\begin{tabular}{|c|c|c|c|c|c|c|c|c|}
\hline \multicolumn{9}{|c|}{$\begin{array}{l}\text { Date: 05/02/15 Time: 21:29 } \\
\text { Sample: 2012M01 2015M02 } \\
\text { Included observations: } 38\end{array}$} \\
\hline Autocorre & lation & Partial & Correlation & & $\mathrm{AC}$ & PAC & Q-Stat & Prob \\
\hline 1 & 1 & 1 & 1 & 1 & -0.015 & -0.015 & 0.0097 & 0.922 \\
\hline 1 C & 1 & & 1 & 2 & -0.059 & -0.059 & 0.1547 & 0.926 \\
\hline $1 \square$ & 1 & 1[ & 1 & 3 & -0.220 & -0.223 & 2.2568 & 0.521 \\
\hline 1 당 & 1 & & 동 & 4 & -0.118 & -0.139 & 2.8807 & 0.578 \\
\hline 1 & I & & 1 & 5 & -0.005 & -0.046 & 2.8817 & 0.718 \\
\hline 14 & 1 & 1 & 맘 & 6 & -0.090 & -0.172 & 3.2683 & 0.775 \\
\hline 1 & 1 & 1 & $\mathbf{I}$ & 7 & 0.068 & -0.013 & 3.4937 & 0.836 \\
\hline 1 & 1 & 1 & 1 & 8 & -0.001 & -0.054 & 3.4937 & 0.900 \\
\hline 1 & 1 & 1 & 무 & 9 & -0.070 & -0.153 & 3.7477 & 0.927 \\
\hline 1 & 1 & 1 & ו & 10 & 0.245 & 0.232 & 7.0173 & 0.724 \\
\hline 1 & 1 & 1 & 1 & 11 & 0.017 & 0.018 & 7.0342 & 0.796 \\
\hline I & 1 & 1 & d & 12 & -0.047 & -0.087 & 7.1648 & 0.847 \\
\hline b & 1 & 1 & $\square$ & 13 & 0.053 & 0.199 & 7.3337 & 0.884 \\
\hline 1 & 1 & 1 & 巨 1 & 14 & 0.037 & 0.117 & 7.4227 & 0.917 \\
\hline 1 & 1 & 1 & 5 & 15 & -0.025 & -0.048 & 7.4629 & 0.944 \\
\hline 1 प् & 1 & 1 & b 1 & 16 & -0.063 & 0.104 & 7.7382 & 0.956 \\
\hline
\end{tabular}

Figura 1 - Correlograma dos resíduos do modelo de previsão da demanda

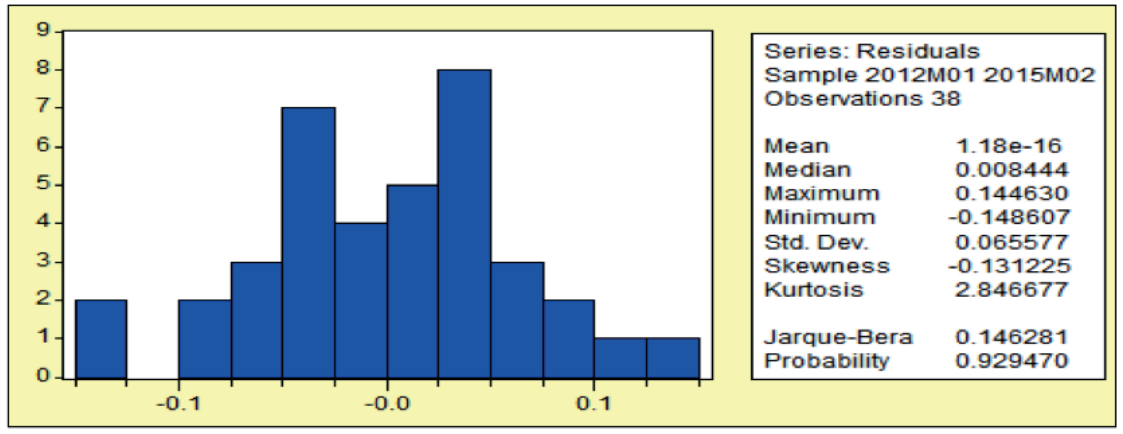

Gráfico 3 - Gráfico do teste de normalidade dos resíduos do modelo de previsão da demanda 
Apesar de usar erros-padrão robustos, foi realizado o teste de White para heterocedasticidade e os resultados indicaram não haver razões para levar a rejeição da hipótese nula de homocedasticidade ao nível de significância de $5 \%$.

Para um nível de significância de $10 \%$ as variáveis significativas foram:

- Variável dependente defasada de um mês;

- Concessões de crédito livre para pessoas físicas defasada de 5 meses

- Taxa de desemprego defasada de 2 meses;

- Crescimento de vendas de móveis e eletrodomésticos defasado de 6 meses;

- Crescimento de vendas de tecidos, vestuário e calçados defasado de 2 meses.

Com a exceção da variável dependente defasada, a relação entre a variação do prêmio ganho e as demais variáveis explicativas é positiva. Ou seja, o modelo indica que quanto maior o volume de concessões de crédito livre a pessoas físicas, efeito defasado de 5 meses, maior será o crescimento do seguro prestamista, o que é intuitivo, visto que é um seguro atrelado a algum financiamento ou empréstimo. Além disso, quanto maior a taxa de desemprego maior é a demanda por este seguro, mas existe o efeito defasado de 2 meses. Isso pode ser justificado pelo receio das pessoas de ficar desempregado e com uma dívida para pagar, mas a percepção não é instantânea. Ademais, como o seguro prestamista costuma ser comercializado em alguns canais de varejo, é razoável ter uma relação positiva com o crescimento de vendas de móveis, eletrodomésticos, tecidos, vestuário e calçados.

\subsection{RELAÇÃO ENTRE A SINISTRALIDADE E A TAXA DE DESEMPREGO}

Para analisar a relação entre a sinistralidade e a taxa de desemprego, foram testadas regressões entre as duas variáveis considerando efeitos de até 12 defasagens. A série histórica utilizada é de janeiro de 2013 a fevereiro de 2015.

À semelhança do modelo anterior, a variável dummy de quebra estrutural por conta da alteração do conceito de prêmio ganho que passou de líquido para bruto de resseguro em dezembro de 2013 não foi significativa. Tal fato deve ter ocorrido pelo resseguro ser baixo no seguro prestamista.

A Tabela 4 mostra o resultado do modelo selecionado. 
Tabela 4 - Resultados do modelo de sinistralidade

\begin{tabular}{|c|c|c|c|c|}
\hline \multicolumn{5}{|c|}{$\begin{array}{l}\text { DEPENDENT VARIABLE: SINISTRALIDADE } \\
\text { METHOD: LEAST SQUARES } \\
\text { DATE: } 05 / 02 / 15 \text { TIME: } 23: 09 \\
\text { SAMPLE (ADJUSTED): } 2003 M 032015 M 02 \\
\text { INCLUDED OBSERVATIONS: } 144 \text { AFTER ADJUSTMENTS } \\
\text { NEWEY-WEST HAC STANDARD ERRORS \& COVARIANCE (LAG TRUNCATION=4) }\end{array}$} \\
\hline VARIABLE & COEFFICIENT & STD. ERROR & T-STATISTIC & PROB. \\
\hline $\begin{array}{l}\text { C } \\
\text { DESEMP(-2) } \\
\text { SINISTRALIDADE(-1) } \\
\text { D_OUTLLER }\end{array}$ & $\begin{array}{l}0.076809 \\
0.542321 \\
0.343355 \\
0.168746\end{array}$ & $\begin{array}{l}0.015250 \\
0.150050 \\
0.060253 \\
0.019889\end{array}$ & $\begin{array}{l}5.036794 \\
3.614276 \\
5.698558 \\
8.484438\end{array}$ & $\begin{array}{l}0.0000 \\
0.0004 \\
0.0000 \\
0.0000\end{array}$ \\
\hline $\begin{array}{l}\text { R-SQUARED } \\
\text { ADJUSTED R-SQUARED } \\
\text { S.E. OF REGRESSION } \\
\text { SUM SQUARED RESID } \\
\text { LOG LIKELLHOOD } \\
\text { DURBIN-WATSON STAT }\end{array}$ & $\begin{array}{l}0.652642 \\
0.645199 \\
0.036958 \\
0.191223 \\
272.6102 \\
1.895384\end{array}$ & $\begin{array}{l}\text { MEAN DEPE } \\
\text { S.D. DEPEN } \\
\text { AKAIKE INFC } \\
\text { SCHWARZ C } \\
\text { F-STATISTIC } \\
\text { PROB (F-STA }\end{array}$ & & $\begin{array}{r}0.196211 \\
0.062046 \\
-3.730697 \\
-3.648202 \\
87.68076 \\
0.000000\end{array}$ \\
\hline
\end{tabular}

Foi utilizada uma dummy (d_outlier) para tratar os outliers, os quais estavam impactando na normalidade dos resíduos.

Pelo teste de Jarque-Bera, para o modelo selecionado, não há indícios que levem a rejeição da hipótese nula de normalidade dos resíduos ao nível de significância de 5\%, conforme Gráfico 4.

Para testar a autocorrelação dos resíduos, procedeu-se ao teste de Durbin-Watson e o de Ljung Box (ver correlograma). Os resultados dos testes efetuados indicaram a ausência de autocorrelação serial ao nível de significância de $5 \%$.

Apesar de usar erros-padrão robustos de Newey-West, foi realizado o teste de White para heterocedasticidade e os resultados sugerem que não há razões que levem a rejeição da hipótese nula de homocedasticidade ao nível de significância de $1 \%$.

O modelo selecionado indica que quanto maior a taxa de desemprego, maior tende a ser a sinistralidade do seguro prestamista, com efeito defasado de 2 meses. Além disso, o poder explicativo do modelo, refletido no R2 ajustado, é de, aproximadamente, 64,5\%. Tal resultado sugere que, como esperado, o desemprego é o principal risco do seguro prestamista, o qual dispõe de outras coberturas, tais como morte, incapacidade temporária e invalidez. 


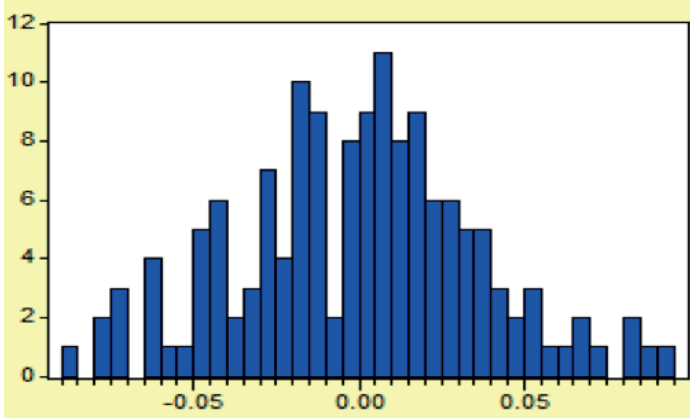

\begin{tabular}{|lc|}
\hline \multicolumn{2}{|l|}{ Series: Res iduals } \\
Sample 2003M03 $2015 M 02$ \\
Observations 144 \\
Mean & $1.79 \mathrm{e}-17$ \\
Median & 0.003304 \\
Maximum & 0.092085 \\
Minimum & -0.089913 \\
Std. Dev. & 0.036568 \\
Skewness & -0.004869 \\
Kurtosis & 2.880981 \\
& \\
Jarque-Bera & 0.085563 \\
Probability & 0.958121 \\
\hline
\end{tabular}

Gráfico 4 - Gráfico do teste de normalidade dos resíduos do modelo de sinistralidade

\begin{tabular}{|c|c|c|c|c|c|c|c|}
\hline \multicolumn{8}{|c|}{ Correlogram of Residuals } \\
\hline \multicolumn{8}{|c|}{$\begin{array}{l}\text { Date: 05/02/15 Time: 23:06 } \\
\text { Sample: 2003Mo3 2015M02 } \\
\text { Included observations: } 144\end{array}$} \\
\hline Autocorrelation & Partial & Correlation & & AC & PAC & Q-Stat & Prob \\
\hline & & & 1 & 0.051 & 0.051 & 0.3847 & 0.535 \\
\hline i & & i曰 & 2 & 0.160 & 0.157 & 4.1535 & 0.125 \\
\hline $1 \boxminus$ & & & 3 & 0.165 & 0.154 & 8.1966 & 0.042 \\
\hline ו & & 1 & 4 & 0.117 & 0.087 & 10.266 & 0.036 \\
\hline ，局 & & i 吕 & 5 & 0.156 & 0.111 & 13968 & 0.016 \\
\hline 㞋 & & & 6 & 0.097 & 0.045 & 15.410 & 0.017 \\
\hline 11 & & 10 & 7 & 0.008 & -0.062 & 15.421 & 0.031 \\
\hline $16 i$ & & i & 8 & 0.053 & -0.015 & 15.860 & 0.044 \\
\hline i i & & i & 9 & 0.072 & 0.035 & 16.668 & 0.054 \\
\hline i & & i & 10 & -0.015 & -0.046 & 16.704 & 0.081 \\
\hline i bi & & & 11 & 0.104 & 0.080 & 18.423 & 0.072 \\
\hline ，白 & & & 12 & 0.105 & 0.108 & 20.162 & 0.064 \\
\hline i & & i & 13 & 0.055 & 0.037 & 20649 & 0.080 \\
\hline$i$ & & i & 14 & 0.075 & 0.020 & 21.568 & 0.088 \\
\hline 1 & & 1 & 15 & 0.004 & -0.049 & 21.572 & 0.120 \\
\hline 11 & & I & 16 & 0.094 & 0.039 & 23.031 & 0.113 \\
\hline i & & 1 & 17 & 0.143 & 0.098 & 26.431 & 0.067 \\
\hline 101 & & 10 & 18 & -0.070 & -0.116 & 27.256 & 0.074 \\
\hline i i & & 1 & 19 & 0.062 & 0.014 & 27910 & 0.085 \\
\hline 151 & & 1 & 20 & 0.053 & 0.035 & 28.391 & 0.100 \\
\hline & & & 21 & -0.031 & -0.055 & 28.555 & 0125 \\
\hline 1 1 & & I & 22 & 0.092 & 0.059 & 30.020 & 0.118 \\
\hline i & & 1 & 23 & 0.048 & 0.053 & 30.420 & 0.138 \\
\hline 1 & & & 24 & 0.087 & 0.085 & 31.745 & 0.133 \\
\hline 10 & & 다 & 25 & -0.057 & -0.135 & 32321 & 0149 \\
\hline ו曰 & & I & 26 & 0.104 & 0.072 & 34.237 & 0.129 \\
\hline 101 & & 1 & 27 & -0.076 & -0.095 & 35.274 & 0.132 \\
\hline 1 1 & & 1 & 28 & 0.068 & -0.010 & 36.110 & 0.140 \\
\hline 1 & & I & 29 & -0.005 & -0.020 & 36.115 & 0.170 \\
\hline 1 & & 1 & 30 & o.00o & 0.030 & 36.115 & 0.204 \\
\hline 1 & & 10 & 31 & -0.039 & -0.055 & 36.401 & 0.232 \\
\hline $1 \mathrm{~b}$ & & $1 \mathrm{~b}$ & 32 & 0.028 & 0.051 & 36.550 & 0.266 \\
\hline $1[1$ & & i & 33 & 0.004 & -0.002 & 36.553 & 0307 \\
\hline 101 & & 101 & 34 & -0.049 & -0.062 & 37.019 & 0.331 \\
\hline ו & & ו & 35 & 0.085 & 0.088 & 38.402 & 0.318 \\
\hline ５， & & ５， & 36 & 0.061 & 0.066 & 39.135 & 0.331 \\
\hline
\end{tabular}

Figura 2 - Correlograma dos resíduos do modelo de sinistralidade

\section{CONSIDERAC̣ÕES FINAIS}

O seguro prestamista é um ramo de seguro que tem por objetivo pagar o saldo devedor ou parcelas de financiamentos/empréstimos/dívidas em caso de ocorrência de eventos previstos nas garantias contratadas, cujas principais 
coberturas, normalmente, incluem perda involuntária do emprego ou incapacidade, temporária ou não, invalidez e morte.

Trata-se de uma modalidade de seguro que tem apresentado uma tendência de crescimento desde 2003, o que ressalta a relevância do presente estudo. Além disso, cabe destacar que, em um ambiente cada vez mais competitivo, para a manutenção de uma gestão eficiente, é muito importante dispor de informações relevantes para tomadas de decisão.

Em seguros, um aumento rápido dos prêmios deve ser analisado com cuidado, a fim de avaliar se tal fato pode ser decorrente de padrões de subscrição inadequados, que podem comprometer a solvência da Companhia no longo prazo. Como os custos das operações, muitas vezes, podem demorar anos até que se tornem efetivamente conhecidos, é relevante compreender e acompanhar as variáveis que influenciam tanto a demanda do seguro quanto a sua sinistralidade.

Nesse contexto, insere-se a presente pesquisa, cujo objetivo foi analisar o segmento de seguro prestamista, buscando identificar possíveis variáveis relevantes para a sua demanda, bem como investigar como a sinistralidade se comporta frente à taxa de desemprego.

Para o desenvolvimento desta pesquisa, fez-se uso de regressões, observandose o fato que nem sempre o reflexo na variável resposta é instantâneo, podendo ocorrer efeitos defasados. Nessa linha, foram testados não apenas os valores correntes das variáveis explanatórias, como também os valores defasados (modelo de defasagens distribuídas), incluindo os valores defasados da variável dependente (modelo auto-regressivo).

Em relação ao modelo selecionado para identificar as variáveis relevantes para prever a variação na demanda do seguro prestamista, além da própria variável resposta defasada de um mês, foram relevantes o volume de concessões de crédito livre a pessoas físicas, a taxa de desemprego e o crescimento de vendas de canais de varejo que comercializam móveis, eletrodomésticos, tecidos, vestuário e calçados.

O modelo indicou que quanto maior o volume de concessões de crédito livre a pessoas físicas, maior será o crescimento do seguro prestamista. Esse resultado é intuitivo porque o seguro prestamista é atrelado, de alguma forma, a algum financiamento ou empréstimo. Mas, o resultado mostrou que o efeito é defasado de 5 meses.

Além disso, o modelo sugere que quanto maior a taxa de desemprego maior é a demanda por este seguro. Esse resultado indica que o receio das pessoas de ficar desempregada e com uma dívida para pagar, influencia na demanda do seguro prestamista, mas a percepção não é instantânea e sim defasada de 2 meses. 
Ademais, como o seguro prestamista costuma ser comercializado em alguns canais de varejo, os resultados sugerem que existe uma relação positiva com o crescimento de vendas de móveis, eletrodomésticos, tecidos, vestuário e calçados, mas também com efeitos defasados.

Em relação ao modelo selecionado para analisar como a sinistralidade se comporta frente à taxa de desemprego, os resultados sugerem que quanto maior a taxa de desemprego, maior tende a ser a sinistralidade do seguro prestamista, com efeito defasado de 2 meses. O poder explicativo do modelo, refletido no R2 ajustado, foi de, aproximadamente, 64,5\%, o que sugere que, como esperado, o desemprego é o principal risco do seguro prestamista, embora disponha de outras coberturas, tais como morte, incapacidade temporária e invalidez. 


\section{REFERÊNCIAS}

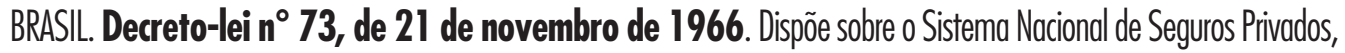
regula as operações de seguros e resseguros e dá outras providências.

CARNEIRO, Luiz Augusto Ferreira (Organizador). Planos de Saúde: aspectos jurídicos e econômicos. Rio de Janeiro: Forense, 2012.

CASTIGLIONE, Luiz Roberto. Seguros: Conceitos e Critérios de Avaliação de Resultados. São Paulo: Manuais Técnicos de Seguros, 1997.

CHAHAD, José Paulo Zeetano. Seguro - desemprego: lições da historia, aspectos e perspectivas para 0 Brasil. São Paulo : Ipe/Usp, 1987.

CHAN, Betty Lilian, SLLVA, Fabiana Lopes da, MARTINS, Gilberto de Andrade. Fundamentos da Previdência Complementar: da Atuária à Contabilidade. 2 ed. São Paulo: Atlas, 2010.

CHAN, Betty Lilian. Risco de subscrição frente às regras de solvência do mercado segurador brasileiro. São Paulo. 2010. Tese (Doutorado em Ciências Contábeis). Faculdade de Economia, Administração e Contabilidade da Universidade de São Paulo.

CONTADOR, Cláudio Roberto, COSENZA, Carlos Alberto Nunes, LNS, Marcos Estellita, GONC,ALVES NETO, Armando C. Avaliação da Performance do Mercado Segurador Brasileiro Através do Método DEA (Data Envelopment Analysis) no Primeiro Semestre de 1999. In: SIMPÓSIO BRASILEIRO DE PESQUISA OPERACIONAL, 32, 2000, Viçosa/MG. Anais do XXXII SBPO. Vicosa: SOBRAPO, 2000.

GUJARATI, Damodar. Econometria Básica. $4^{\mathrm{a}}$ ed. Rio de Janeiro: Campus, 2006

IBGE. Pesquisa Mensal de Emprego. Disponível em: < http://www.bge.gov.br/home/estatistica/indicadores/ trabalhoerendimento/pme_nova/default.shtm>. Acesso em 24.fev.2007.

LUCCAS FILHO, Olivio. Seguros: fundamentos, formação de preço, provisões e funç̃oes biométricas. São Paulo: Atlas, 2011.

MACEDO, Marcelo Álvaro da Silva, SILVA, Fabrícia de Farias da, SANTOS, Rodrigo Melo. Análise do Mercado de Seguros no Brasil: Uma Visão do Desempenho Organizacional das Seguradoras no Ano de 2003. Revista Contabilidade \& Finanças. Ano XVII, vol. 5, Especial Atuária, Dez/2006.

MANKIW, N. Gregory. Princípios de Macroeconomia. $3^{\circ}$ ed. São Paulo: Pioneira Thompson Learning, 2005. MYHR, A. E; MARKHAM, J. J. Operações, Regulamentação e Contabilidade de Seguros. Rio de Janeiro: FUNENSEG, 2006.

SINGER, Paul. Globalização e desemprego: diagnóstico e alternativas. São Paulo: Contexto, 1998. SOUZA, Edna. Caminhos para o Desenvolvimento. Revista de Seguros. Ano 87, n 859, Out/Nov/Dez 2006.

SOUZA, Silney. Seguros: Contabilidade, Atuária e Auditoria. São Paulo: Saraiva, 2002.

Superintendência de Seguros Privados (SUSEP). Anuário Estatístico da SUSEP 1997. Guia de Orientação e Defesa do Segurado. Junho de 2006.

. Relatório Mensal de Acompanhamento do Mercado Supervisionado. Janeiro de 2007. Disponivel em: <http://www.susep.gov.br Acesso em 23 fev. 2007. 
